\title{
The Performance of Medical Laboratory Technician Based on Situation Awareness and Psychological Capital with the Work Engagement Mediation
}

\author{
Muhamad Muslim, Fendy Suhariadi2, Nyoman Anita Damayantiz, Windhu Purnomoz \\ ${ }_{1}$ Doctoral Program of Public Health Faculty, ${ }_{2}$ Faculty of Psychology, \\ ${ }_{3}$ Faculty of Public Health, UniversitasAirlangga Surabaya, Indonesia
}

\begin{abstract}
The result of laboratory examination in three districts of South Kalimantan, as much as $36,36 \%$ has good quality examination and $63,64 \%$ has not good. These facts prove that the performance of laboratory technician who do the analysis of the test material is still not good and the performance is influenced by organizational factors and individual workers. The purpose of this study was to analyze the performance of medical laboratory technician based on individual factors of situation awareness and psychological capital that can influence the performance with the work engagement mediation. This type of the research was an observational analytic study and cross sectional design with 150 subject samples. The result that the situation awareness has a significant effect on performance with regression coefficient 0.242 with $p$-value $<0.001$ or critical ratio value 3.5 bigger than critical t-statistic value at $95 \%$ with confident interval $(\geq 1.96)$. Psychological capital has a significant effect on performance with unstandardized regression coefficient of 0,239 with p-value $<0.001$ or critical ratio value equal to 3,095 bigger than critical t-statistic value at $95 \%$ confident interval $(\geq 1.96)$. Situation awareness and psychological capital have a positive effect on work engagement. The identification of influence relationships shows that the situation awareness and psychological capital affect the performance of medical laboratory technician and mediated by work engagement.
\end{abstract}

Keywords: situation awareness, psychological capital, work engagement and performance.

Corresponding author:

Muhamad Muslim

Doctoral Program of Public Health Faculty

UniversitasAirlangga Surabaya

E-mail : muslim3567@gmail.com

Introduction

Medical Laboratory is a health laboratory conducting medical specimen examination service to get information about individual health especially to support disease diagnosis, healing disease and health restoration. ILaboratory performance can be determined through assessment of the results of inspection or analysis of materials or specimens performed by laboratory personnel. The evaluation result of the National Program for External Quality Consolidation for Medical Chemistry during 2013 in three laboratories of District General Hospital in Kalimantan Selatan showed 36.36\% good quality inspection and $63.64 \%$ was not good. It can be interpreted that the performance of the hospital laboratory, especially on medical chemistry parameters was still not good, although the hospital laboratory has been supported by infrastructure facilities such as building and laboratory equipment, human resources (laboratory technician), as well as materials or reagents according to standard laboratory services. This fact is evidence that the performance of laboratory personnel who conducted the analysis of the test material was still not good. The measurement of laboratory techinician performance can use several performance dimensions of quality, quantity, and timeliness.2 Factors that may affect the performance of medical laboratory technician include organizational and individual factors. 3 So to improve the performance of laboratory technician in the service, need to know the most influential factors to improve the performance of technicians. The purpose of this study was to analyze the performance of medical laboratory technicians based on individual factors of situation awareness and psychological capital officials who can influence the performance with work engagement mediation.

Materials and Method

Analytical observation research uses cross sectional approach to know the relationship or influence between exogenous variables on endogenous variables by measuring the situation awareness, psychological capital and 
work engagement as mediator on the performance of medical laboratory technicians in the hospital service at one time (point time approach). The study in this research was to look for each influence of exogenous variable that is; situation awareness and psychological capital to endogenous variables namely; work engagement and performance of medical laboratory technician. This study aims to find and build a theoretical model of influence situation awareness and psychological capital on the performance of medical laboratory technician with work engagement as a mediator to be tested empirically. Population in this research is medical laboratory technician that consist; Medical Laboratory Technologist (ATLM), paramedics and head of installation as well as in charge of the hospital laboratory at the district in BanuaAnam (six districts) of Kalimantan Selatan province, namely; (1) General Hospital of Datu Sanggul, Tapin District (2) General Hospital of H. Hasan BaseryKandangan, Hulu Sungai Selatan District (HSS), (3) General Hospital of H. Damanhuri Barabai, Hulu Sungai Tengah District, (4) General Hospital of PambalahBantungAmuntai, Hulu Sungai Utara District, (5) General Hospital of Balangan and (6) General Hospital of H. BadrudinTanjung, Tabalong District. Determination of the sample size using Slovin formula and the minimum rule required by Structural Equation Modeling (SEM) analysis, then from both approaches will be taken an adequate sample size and done by random sampling technique, and got the number of samples of 150 subjects. The instrument that used in this research was a scale to measure situation situation awareness, psychological capital, work engagement and performance of medical laboratory technician. Items are arranged based on each research variable that is downgraded to dimension or sub variable, then the indicator of each dimension or sub variable is made, from the indicator is prepared the question items. The scale is pre-tested on a limited basis with small samples $( \pm 30)$ and then consulted with the expert and then tested the validity and reliability. Validity test is done by using Karl Pearson product moment correlation coefficient. Scale is reliable if the respondent's answer to the statement is consistent or stable over time. Reliability test is based on Alpha Cronbach value, if Cronbach Alpha value> 0.60. Data analysis using univariate analysis to get picture of characteristic variable and frequency of each variable. Structural Equation Modeling (SEM) analysis was used to analysis the effect of situation awareness and psychological capital variables and work engagement mediation on the performance variables.

\section{Results and Discussion}

Result of data analysis on regression coefficient of structural model relationship between the situation awareness variable, psychological capital, work engagement, and performance of medical laboratory technician shows that all relationships between variables are significant. The situation awareness has a significant effect on the performance of medical laboratory technician. This is shown by unstandardized regression coefficient of 0.242 with p-value $<0.001$ or critical ratio value of 3.5 bigger than the critical tstatistical distribution value at $95 \%$ confidence interval $(\geq 1.96)$. Situation awareness also has a positive effect on work engagement. This is indicated by unstandardized regression coefficient of 0.621 with $\mathrm{p}$ value $<0.001$ or critical ratio value of 5.644 greater than the critical tstatistical distribution value at $95 \%$ confident interval (> 1.96). Psychological capital has a significant effect on the performance of medical laboratory technician. This is indicated by unstandardized regression coefficient of 0.239 with p-value $<0.001$ or critical ratio value of 3.095 bigger than the critical t-statistical distribution value at $95 \%$ confident interval $(\geq 1.96)$. Psychological capital also has a positive effect on work engagement. This is shown by unstandardized regression coefficient of 0.975 with $\mathrm{p}$ value $<0.001$ or critical ratio value of 11.066 greater than the critical t-statistical distribution value at $95 \%$ confident interval (> 1.96). The identification result of the relationship showed that the situation awareness (regression coefficient 0.757 ) and psychological capital (regression coefficient 1.111) have an effect on to the performance of medical laboratory technician and mediated by work engagement. The situation awareness can directly affect the performance of laboratory technician, but the effect is greater when mediated by work engagement. The situation awareness can affect performance. 4 Other research is suggested that situational awareness has a great positive effect on one's performance. Situation awareness is a variable that gives a lot of influence to performance, and the rest is influenced by other variables.5The results showed that laboratory technician with perception level in high situation awareness, also most have high quality of work in high performance. The percentage of medical laboratory technician with low work engagement will be followed by low laboratory staff performance. This relate with the research that also states that employee's work and performance work have a very direct relationship, if the employee's work engagement is high, will have an impact on high performance, and vice versa.6 Situation awareness with mediated work engagement has a significant effect to improve the performance of medical laboratory technician. The situation awareness is 
related to performance in terms of understanding and predictions of technician performance and is a primary goal in analyzing human factors, their interactions and actions in the environment. 7 The interaction and actions of technicians with their fellow technicians and good working environment will make good relationships between technician each others with their work environment, if good technician relations are created then work engagement can also be realized because of the good condition among fellow technicians as well as the environment has been created well. Interaction between employees and employers as a form of performance attachment can be realized with the situation awareness is good by workers. Creation of a good relationship is one of the images or reflection of positive employee performance.s A good awareness of the situation will affect the quality of the decision and subsequently the quality of the decision will affect the performance, otherwise misperception, understanding, and prediction will result in faulty decision making, then performance will be bad.9 Inability to do situation awareness is one of the factors causing errors or human error in pre analytic and analytic stages. Situational awareness is an ability to identify, analyze and translate comprehensively the critical elements of information about what happened.7 Psychological capital (PsyCap) has a positive effect on the performance of medical laboratory technician. This corresponds to another study which states that PsyCapis related to the performance.10 Overall PsyCap (hope, self-efficacy, reslience, optimism) as a multidimensional construct has a positive effect on the performance. ${ }_{11}$ PsyCap can have a direct positive effect on performance, but the effect is greater when mediated by work engagement. High-level of PsyCap concepts relate to high-level work engagement and organizational commitment. ${ }_{12}$ Optimism as a dimension of PsyCap is mediated by the organizational effort, reward, and support factor in influencing work engagement (vigor, dedication, and absorption) furthermore it will affect performance. The laboratory technician who has a good morale, has confidence in his job, and can solve the problem well, will make the officer more enthusiastic in working with positive energy on him, make the officers more enthusiastic in working, and feel happy with his work. Engagement in the high levels will have a positive effect on the performance in the higher levels of groups, units, and organizations.11 The engagement work of employees and performance have a direct proportional relationship, that is, if high work engagement will have an impact on high performance of employees, and vice versa..Employees who are fully engaged will feel good about the work they do and increase the employment attachment when carrying out the work.8 So PsyCap of medical laboratory technician mediated with work engagement will also be able to significantly improve officer performance. Therefore, it is necessary to increase the knowledge of the officer regarding the situation awareness and psychological capital combined with the improvement of work engagement to the medical laboratory technician so that the performance of the officer also increases. The improvement of situation awareness is done by increasing the knowledge of the technician with special orientation and training and is associated with the attachment of work to all laboratory technicians regarding the various environment around the laboratory, the various actions and risks of action, and other information that should be understood by all officers including in all services, as well as events that may occur in the performance process of medical laboratory technician. To improve the performance of medical laboratory technician, it is necessary to increase the PsyCap which is mediated by work engagament such as regular or routine motivation to the officer with routine activity which is also done as bonding effort to laboratory officer with work environment and with coworkers.

\section{Conclusion}

The situation awareness and psychological capital affect the performance of laboratory technician and mediated by work engagement. So to improve the performance of medical laboratory technicians, we need to increase the knowledge of technicians about the situation awareness that can be done with a special orientation to the technicians and training. The improvement of psychological capital mediated by work engagament can be done by giving motivation routinely as effort of bonding performance of medical laboratory technician with work environment and also colleagues.

Ethical Clearance: Before conducting the data retrieval, the researchers conducted a decent test of ethics conducted at the Faculty of Public Health Airlangga University to determine that this study has met the feasibility. Information on ethical test on March 16, 2016 that the study is eligible to continue. The feasibility of the research was conducted in an effort to protect the human rights and security of research subjects.

Source Funding: This study done by self funding from the authors.

Conflict of Interest: The authors declare that they have no conflict interests. 


\section{References}

[1] Hidayah EN, Aditya W. Potential and effects of plants on domestic wastewater with constructed wetland system. Journal of Environmental Engineering Science. 2010; 2(2): 11-18.

[2] The Ministry of Health. 2010. The Regulation of Ministry of Health No. 411 / Menkes / PER / III / 2010 about Clinical Laboratory. Ministry of Health of the Republic of Indonesia.

[3] Bernardindan Russel.1993.Human Resource Management.New Jersey: International Editions Upper Saddle River, Prentice Hall.

[4] Gibson, et al.1996. Organization, Behavior, Structure, Process.BinaRupaAksara. Jakarta.

[5] Durso, F. T., Hackworth, C. A., Truitt, T. R., Crutchfield, J., \& Nikolic, D. 1999. Situation Awareness as A Predictor of Performance in En Route Air Traffic Controllers (No.DOT/FAA/AM-99/3). Oklahoma Univ Norman Dept of Psychology.

[6] Rosyidha, M. Putro, S.C., Rahmawati, Y. 2015. The Influence of Lecturer Example and Pedagogical Knowledge to the Situational Awareness of Student Candidate for Electrical Engineering Department. TeknologidanKejuruan. Vol.38(2),p:147-156.

[7] Bailey, C. et al. 2015. The Meaning, Antecedents and Outcomes of Employee Engagement: A Narrative Synthesis. International Journal of Management Reviews. Vol.4 (1), p: 31-53.

[8] Parasuraman, A., Zeithaml, V.A. \& Berry, L.L. 1988. "SERVQUAL: a multiple item scale for measuring consumer perceptions of service quality", Journal of Retailing, Vol.64(5), p: 21-40.

[9] Liwarto, I.N., Kurniawan, A. 2015. The Relationship of PsyCap with Employee's Performance PT.X Bandung. JurnalManajemen. Vol.14(2).

[10] Endsley. Mica R., Bolte, Betty and Jones. Debra G. 2003. Designing for Situation Awareness An Approach to User-Centered Design. London and New York: Taylor \& Francis.

[11] Kappagoda, S., Othman, P., Fithri, H. Z., \& Alwis, G. D. 2014. Psychological Capital and Job Performance: The Mediating Role of Work Attitudes. Dr. Hohd. ZainulFithri and Alwis, Gamini De, Psychological Capital and Job Performance: The Mediating Role of Work Attitudes. Journal of Human Resource and Sustainability Studies.

[12] Asmara, A.P. 2017. The Analysis of the Effect of Turnover Intention on Work Engagement and Employee's Performance. Essay. Universitas Airlangga: Surabaya.

[13] Simons, J. C. AndBuitendach, J. H. 2013. Psychological Capital, Work Engagement and Organizational Commitment Amongst Call Centre Employees in South Africa. SA Journal of Industrial Psychology, 39 (2), p. 1-12. (13). 